\title{
THE COAT COLOR OF MOLES
}

\section{By Loye Miller}

Castle, ${ }^{1}$ in his studies of color inheritance in various domestic rodents, learned that the gray coat of wild rabbits is highly complex in its nature, the resultant of joint action of several independent factors, and that the various color phases known to the rabbit fancier are but the effect of weakening or loss of one or more of these factors. He recognizes in the rabbit no less than eight such factors and offers as evidence of their presence, the mathematical results obtained in cross breeding. Any one who will follow the account of his experiments with some measure of care will perforce admit the weight of his conclusions and will concede that the methods of analysis by careful pedigreed cross breeding approach in accuracy the work of an analytic chemist.

The eight factors established for the rabbit are as follows:

1. A color factor, necessary to the formation of all pigment and absent in albinos.

2. A factor for black.

3. A factor for brown.

4. A factor for yellow.

5. A factor for intensity of color.

6. A factor for pattern of individual hairs.

7. A factor for self coloration, i.e., no white spotting.

8. A factor for extension of dark pigments from extremities of ears and feet.

This formidable array of color factors, each acting as an entity in transmission through the generations, can be proven only from the record of tremendous numbers of cross matings under absolute control, hence such proof is out of the question in a wild race. However, by taking account of seeming parallelism and by making use of the occasional sporadic aberrant that comes to the hand of the field naturalist, some pardonable conjecture may be formulated.

The very interesting account by Patterson ${ }^{2}$ of a cinnamon phase of the roof rat, developing in Travis County, Texas, represents such a case. The rat in an animal that can usually be kept in captivity and reared in large numbers, so attempts to breed the new cinnamon roof

${ }^{1}$ Castle, W. E., Studies of Inheritance in Rabbits, Carnegie Inst. Publ., 1909, p. 45 .

${ }^{2}$ Patterson, J. T., Science, n.s., vol. LII, no. 1341, p, 250, 1920. 
rat are doubtless ere this proving successful. Results with some of our less domestic and less amenable animals are harder to obtain, hence any light that the field naturalist can shed upon the subject should be welcomed. It is to encourage the reporting of such sporadic cases and possibly to contribute to a slowly accumulating fund of evidence, that this note is offered for publication.

An abnormally colored specimen of the southern California mole, Scapanus latimanus occultus, was recently placed in my hands by a student who had captured it in a gopher trap in the city of San Gabriel, California. The specimen is, to my way of thinking, far more interesting than an ordinary case of albinism. It is not an albino but is light cinnamon yellow in color. This pigment, with the glistening quality of the mole's fur, results in a beautiful golden effect quite pleasing to the eye. It seems to me that this particular blunder on the part of nature has an even greater interest beyond its beauty in that it may throw some light upon the color composition of the mole.

The normal color of the species under discussion is, at first impression, a uniform slate gray with silvery reflections. This uniformity is notable in nestlings, in half grown, and in adult specimens. It applies to the individual hair from practically its base to its tip as well as to the entire body of the animal. Only on the extreme margins of the lips or upon the nearly bare feet and tail do we find a lighting up of the dark slate monochrome by whitening of the hairs. The simplest conclusion would be that color in the mole is due to a single heritable factor even as color in the human negroid was at one time supposed to be. Those who have seen the startling results of segregation of determiners displayed in red-haired mullatos may be ready to concede the possibility of complexity in the slate monochrome of moles.

\section{MICROSCOPIC STUDY OF THE HAIR}

The fully developed hair of the southern California mole is a structure of varying diameter with very thick cortex and relatively small medulla. A succession of three or four constrictions of both cortex and medulla, resulting sometimes in complete loss of the latter, is noticeable between base and tip of hair. The hair is narrow at its base and is widest in a region near the tip whence it begins to taper off to a point. Along the medulla the pigmented areas appear as dark masses resembling bubbles of india ink regularly distributed along a capillary glass tube, except that they are more like dises than bubbles 
and their thickness is commonly less than their diameter. The space between discs is but slightly greater than the thickness of the disc. In the regions of constriction the form of the color masses becomes modified by a reversal of proportions and they become elongated to styliform proportions before being finally pinched out by loss of the medulla. Throughout the major portion of the hair the colored areas appear perfectly black. However, where they are thinned out by terminal or intervening constriction of the medulla the last ten or twelve become progressively less purely black until the terminal style appears dark umber brown. This appearance is less marked in the intermediate constrictions than in the terminal one and is nowhere revealed except by careful scrutiny. The proportion of these brownish areas is so small and the difference in color is so slight that the effect is entirely lost in viewing the pelt as a whole.

The cortical part of the hair is glistening white and clears to almost complete transparence. Only at rare and irregular intervals is a slight rusty stain visible. The thickness of the cortex and its freedom from color are probably responsible for the silvery sheen of the mole's fur.

Hairs were cleared in carbol-xylol to reduce the effect of air bubbles in microscopic study.

\section{HAIR OF THE NESTLING MOLE}

In a nestling so young that the hair lies flat and is quite stiff, the color is identical with that of the fully adult animal. There is the same monochrome pattern of the pelt as a whole, and the same lack of pattern in the individual hair, except where constriction, obliterating the medulla, leaves but the silvery cortex. In the specimen at hand the hair is so short that there is but one of these constrictions, that at the base of the hair, instead of three or four as seen in the adult. There can be no question then that the hair is fresh and unabraded. There appears the same slight rusty stain in the cortex in about the same degree as in the adult. The color areas are indistinguishable from those of the adult. Where the pigment becomes thinned out at the constrictions, the same umber brown is evident. It is a question then, so far as microscopic study of the normal mole is concerned, whether the color area carries a single pigment which is so darkly brown as to appear black or bears a black and a yellow pigment intimately commingled. Study of the hair with the oil immersion lens failed to disclose a commingling of individual granules of pigment of different colors. If 
there be a genetic complex of color determiners present in the mole, as has been demonstrated for various rodents, it can not be seen that they affect different granules. The commingling must be ultramicroscopic.

\section{STUDY OF THE XANTHIC SPECIMEN}

The aberrant specimen that precipitated this discussion shows no departure from the normal beyond that of the color areas of the hair. Palms, soles, claws, and the nearly naked skin of the tail and the nose are, like those of the normal animal, practically without pigment and I can distinguish no difference between the two color phases in respect to the coloration of these parts. In preparing the skin, the eye rudiments were visible and there was noticed no difference between them and the rudiments in normal moles. Unfortunately no microscopic examination of these parts was made, so we lack proof for the assumption that the eye color was normal.

Microscopic study of the hair shows no divergence from the normal except in the matter of color of the pigment. The color areas are present and they in every other respect correspond with those of normal moles, but they are light brownish yellow instead of dense black in tone. They are readily marked off from the adjacent spaces and from the colorless cortex. The same styliform effect occurs where the medulla is constricted. Altogether, there is no reason for considering the specimen as an albino in which the whole machinery of pigmentation is lacking.

Whatever the theory of pigmentation toward which one may lean, it seems to me that this specimen represents the result of a factor dropped out, a chemical radical split off, a poverty in tyrosinase, or what you will, and that it serves somewhat to prove the complexity of color in a seemingly simple monochrome species of mammal.

Southern Branch Univ. of California, Los Angeles, Calif. 


\section{$2 \mathrm{BHL}$ Biodiversity Heritage Library}

Miller, Loye. 1921. "The Coat Color of Moles." Journal of mammalogy 2, 163-166. https://doi.org/10.2307/1373605.

View This Item Online: https://www.biodiversitylibrary.org/item/220033

DOI: https://doi.org/10.2307/1373605

Permalink: https://www.biodiversitylibrary.org/partpdf/90596

\section{Holding Institution}

Smithsonian Libraries

\section{Sponsored by}

Biodiversity Heritage Library

\section{Copyright \& Reuse}

Copyright Status: Not in copyright. The BHL knows of no copyright restrictions on this item.

This document was created from content at the Biodiversity Heritage Library, the world's largest open access digital library for biodiversity literature and archives. Visit BHL at https://www.biodiversitylibrary.org. 